\title{
EEN NIEUW COLLECTIEBOEK
}

Precies dertig jaar na het verschijnen van Asiatic Art in the Rijksmuseum, Amsterdam is er een nieuw collectieboek: Aziatische Kunst. Het is in het Nederlands en het Engels (Asian Art) uitgebracht. In het boek zijn 119 objecten opgenomen die alle royaal zijn afgebeeld en toegelicht, bijna altijd met een steun- of detailafbeelding. Formaat en dikte van het boek zijn gegroeid ten opzichte van het exemplaar van dertig jaar geleden, maar de indeling komt min of meer overeen: het opent met een introductie over de geschiedenis van de collectie, geschreven door Pauline Lunsingh Scheurleer. Daarna volgen de voorwerpen, gegroepeerd naar cultuurgebied. Het zijn de eigen Rijksmuseumconservatoren die deze beschrijvingen voor hun rekening hebben genomen. Anna Slaczka schrijft over Zuid-Aziatische kunst, William Southworth over Zuidoost-Aziatische kunst, Menno Fitski over Japanse kunst. Voor twee gebieden moest expertise van buitenaf worden ingeroepen. Rose Kerr, het voormalig hoofd van de Aziatische afdeling van het Victoria \& Albert Museum in Londen, heeft de Chinese selectie gemaakt en de voorwerpen beschreven; Charlotte Horlyck van het British Museum heeft Korea voor haar rekening genomen. Het boek wordt besloten door mijn hoofdstuk over Aziatische voorwerpen die speciaal voor de export naar Europa zijn vervaardigd.

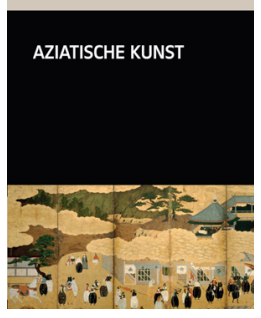

De hoofdstukken openen steeds met een korte inleiding, waarin zeer bondig de kunsten uit het betreffende cultuurgebied worden besproken. Het is een haast onmogelijke opgave om heel bondig te schrijven over zulke grote gebieden en de culturen die zich over vele eeuwen uitstrekken. Toch werkt het goed om een aantal hoofdlijnen aan te duiden. Veel onderzoek dat in de afgelopen jaren naar de collectie is verricht, krijgt in de beschrijvingen van de objecten in beknopte vorm zijn weerslag. Achter in het boek is een lijst opgenomen met per voorwerp literatuurverwijzingen voor degenen die hierover meer willen weten. Bibliografie en index maken het boek compleet en bruikbaar.

Aziatische Kunst is de eerste uitgave van een reeks die het Rijksmuseum over de eigen collectie uitgeeft. Sinds de heropening van het museum in 2013 kan de bezoeker een chronologische wandeling maken door de Nederlandse cultuurgeschiedenis vanaf de Middeleeuwen tot en met de $20^{\mathrm{e}}$ eeuw. Schilderkunst, toegepaste kunst en historische voorwerpen zijn in deze nieuwe opstelling samengebracht en per eeuw verschijnt een boek over deze veelomvattende en veelzijdige collectie. Omdat de Aziatische kunst een eigen paviljoen heeft gekregen, heeft het museum besloten over deze collectie in dezelfde serie een eigen boek uit te brengen. De bekende Nederlandse vormgeefster Irma Boom verzorgt de huisstijl en grafische vormgeving voor het museum en heeft dus ook ons collectieboek vormgegeven. Dankzij hadar o2:36:42PM 
52

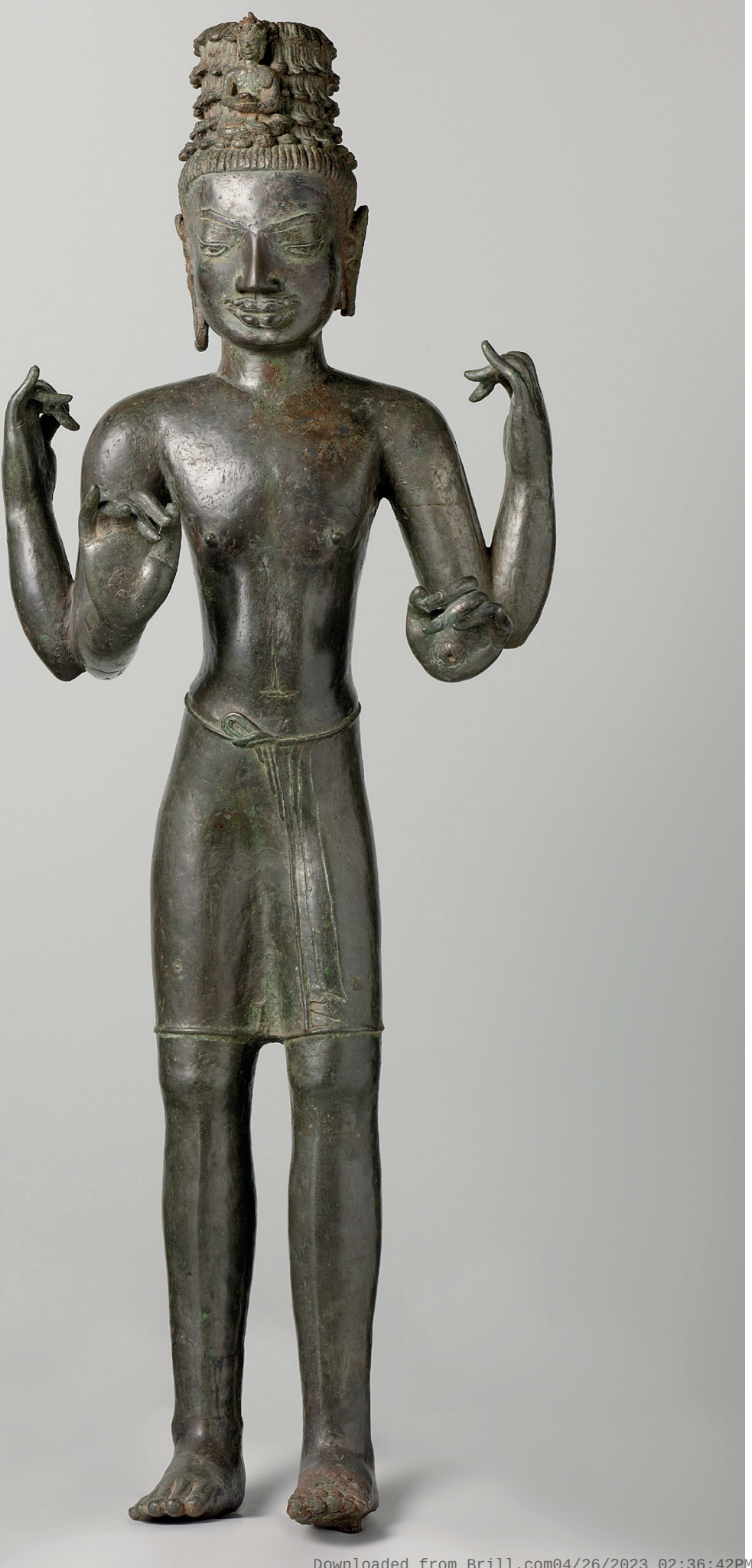


heldere stijl en de fraaie Rijksmuseumfoto's is het een plezier om door het boek te bladeren.

Afb. 2

De bodhisattva

Avalokiteshvara, brons, h. $79 \mathrm{~cm}$., Thailand, Buriram, 750-800, Rijksmuseum Amsterdam, inv.nr. AK-RAK-2000-15.
Deze nieuwe publicatie brengt twee gezichtspunten naar voren die misschien niet geheel verrassend zijn, maar toch de aandacht verdienen. In de eerste plaats is dat het evidente belang van de Vereniging van Vrienden der Aziatische Kunst voor het Rijkmuseum. Iets meer dan de helft van de voorwerpen die in Aziatische Kunst zijn opgenomen, behoren tot de collectie van de VVAK. Het is goed dat dit boek opnieuw (Maartje Draak schreef een uitstekende geschiedenis van de vereniging in het vorige collectieboek) de geschiedenis van de VVAK bevat. Pauline Lunsingh Scheurleer plaatst deze geschiedenis echter veel meer in de algemene context van de belangstelling voor Aziatische kunst in Nederland en de Westerse wereld en in de verzamelen tentoonstellingsgeschiedenis van Aziatische kunst in het Rijksmuseum. Het is vanuit dat gezichtspunt dan ook logisch dat het boek nu een hoofdstuk over exportkunst bevat, iets wat in 1985 niet het geval was, en ook niet de bedoeling.

Het tweede gezichtspunt is het belang van de verwervingen sinds 1985 . Maar liefst 29 van de 119 voorwerpen hebben Vereniging of Rijksmuseum verworven sinds het verschijnen van het vorige collectieboek. Dat is een substantieel aantal en tussen die nieuwe stukken zitten beeldbepalende voorwerpen: belangrijke beelden van Vishnu uit Kashmir (nr. 3), Durga uit Bangladesh (nr. 6) en Somaskanda (nr. 10) hebben de kunst uit India aanmerkelijk versterkt. Hetzelfde geldt voor de afdeling Zuidoost-Azië voor het beeld van De bodhisattva Avalokiteshvara uit Thailand (nr. 32). En natuurlijk geldt het par excellence voor de Japanse tempelwachters (nr. 73), een prachtige versterking die de collectie Japanse boeddhistische beeldhouwkunst veel veelzijdiger maakte en die zonder twijfel de beeldbepalende stukken zijn geworden voor de Japanse kunst in het museum.

\section{- Aziatische Kunst / Asian Art}

Jan van Campen, Menno Fitski, Charlotte Horlyck, Rose Kerr, Pauline Lunsingh Scheurleer, Anna Slaczka, William Southworth. Translation/text editing Lynne Richards, Philip Clarke Rijksmuseum, Amsterdam, 2014, 317 pagina's, 119 platen, full colour, gebonden. ISBN 789071450716.€40,00

Er is zowel een Nederlandse als een Engelse editie. De boeken zijn verkrijgbaar in de winkel van het Rijksmuseum of via www.rijksmuseum.nl/shop 
De soetrakist voor (boven) en na (onder) restauratie;

hout, lak, parelmoer, metaal-draad, $34 \mathrm{x}$ $49,5 \times 27,5$ cm., Korea, Koryo-periode (9181392), Rijksmuseum Amsterdam,

inv.nr. AK-MAK-178. Bruikleen van de VVAK, verwerving 1972.

Foto boven:

Victor Snoek.

Foto onder:

Rijksmuseum

Amsterdam.
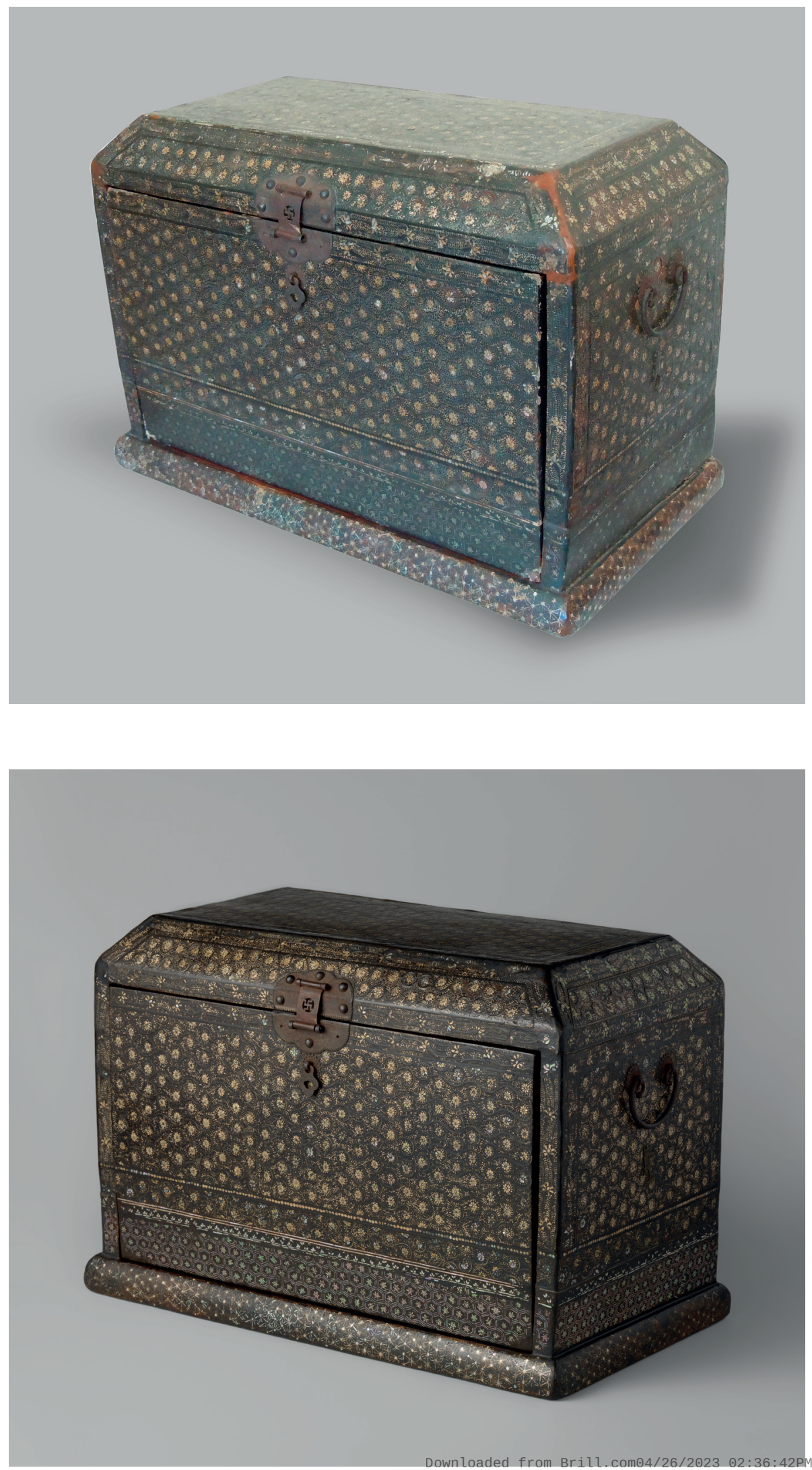

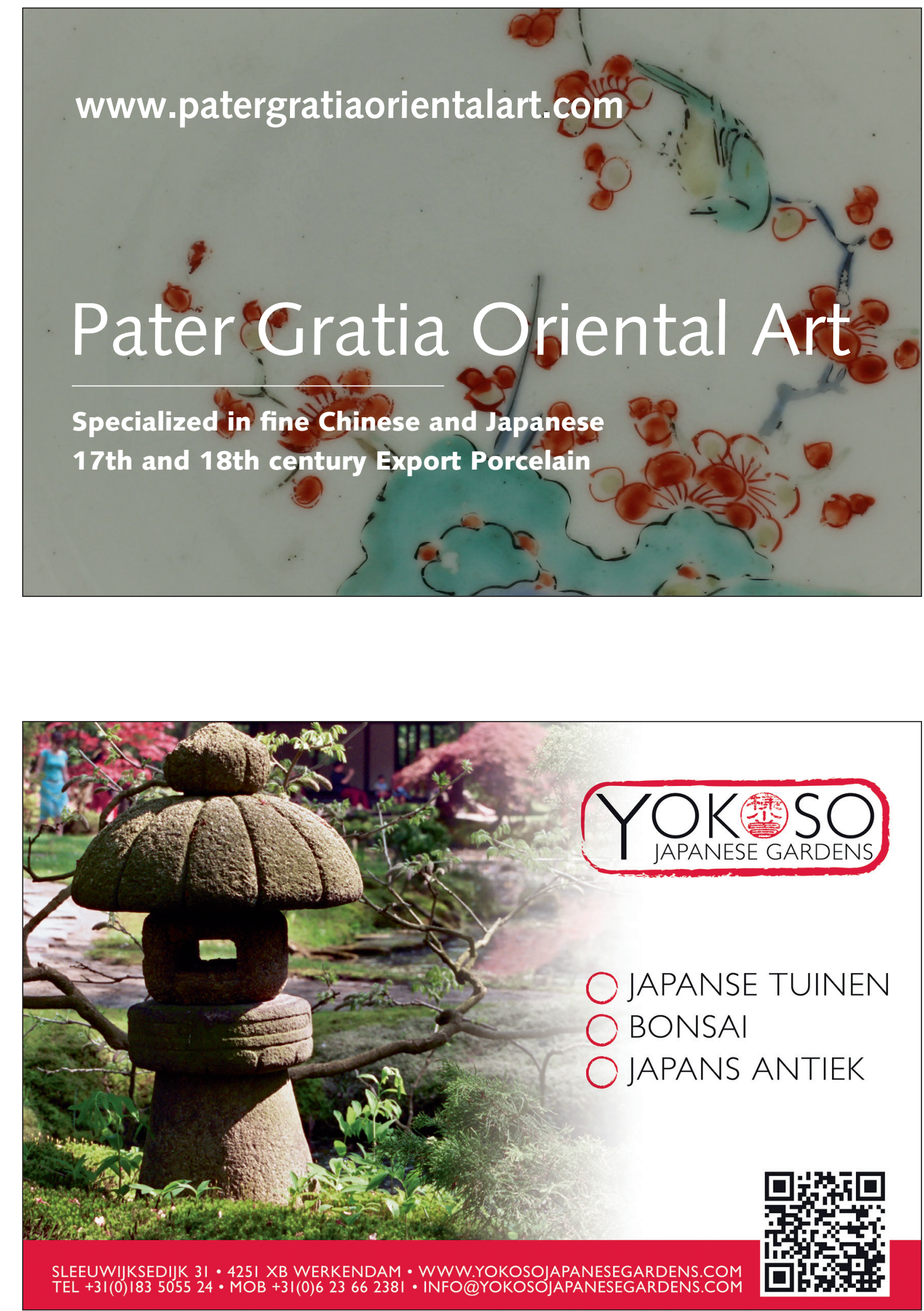

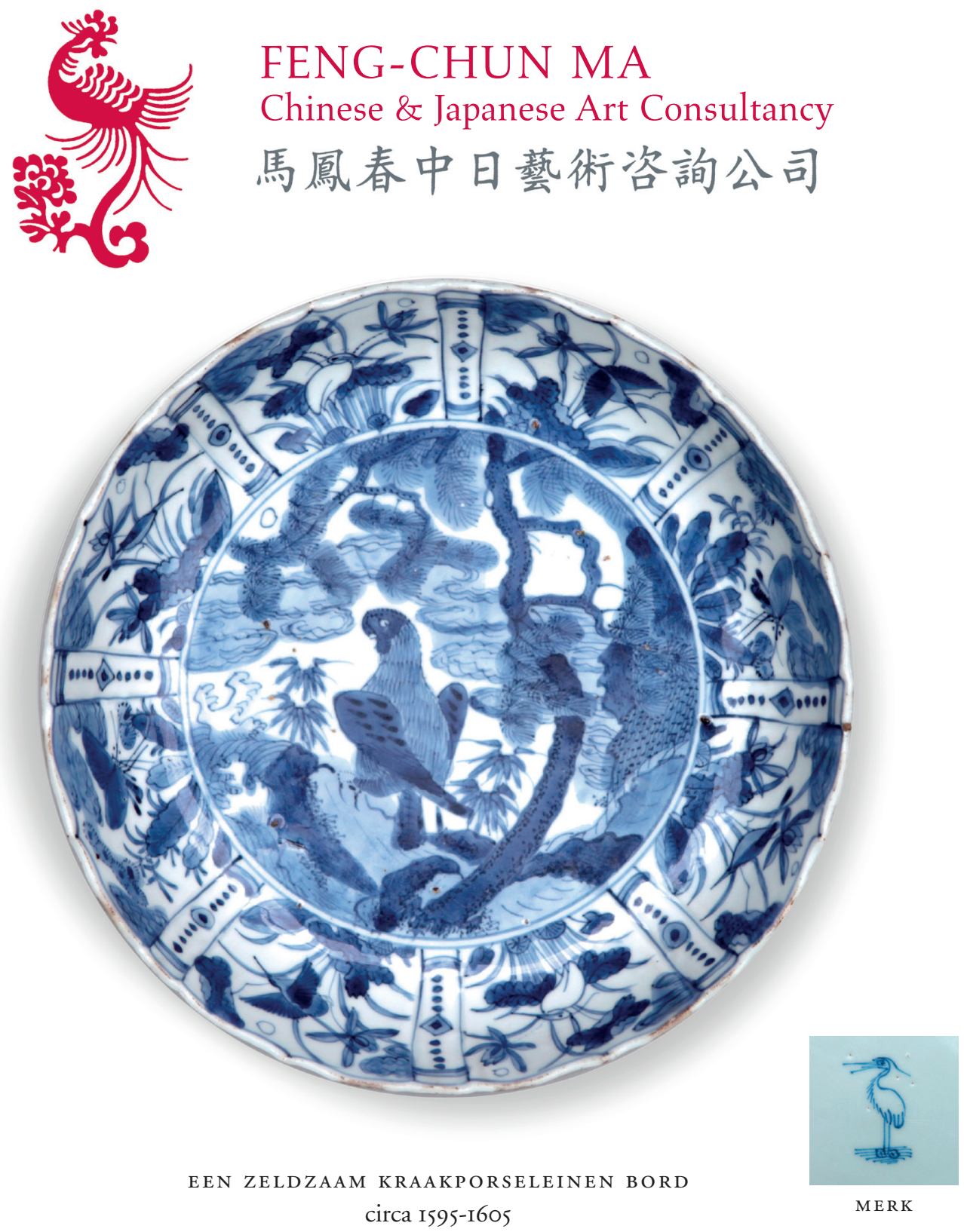

Beschilderd met een adelaar op een rots, Herkomst: Nederlandse privé-verzameling omringd door panelen met reigers en insecten, de onderkant gedecoreerd met hommels en lingzhi, de bodem met 'ooievaarsmerk' Diameter $20 \mathrm{~cm}$. Geillustreerd door M. Rinaldi in Kraak Porcelain: A Moment in the History of Trade, Londen, 1989, pl. 263. Dit is het enige bekende exemplaar in dit type Kraakporselein.

Meer informatie kunt $\mathrm{u}$ vinden op onze nieuwe website. Uitsluitend op afspraak.

Weerdestein 1821083 GM Amsterdam Tel: 31 (0)20 4208248 Fax: 31 (0)20 4208724

Website: www.fengchunma.com E-mail: fcma@fengchunma.com 


\section{BASTINGS ANTIQUAIRS}

Al meer dan 50 jaar specialisatie van o.a. Chinees en Japans porselein uit de $16^{\mathrm{e}} \mathrm{t} / \mathrm{m}$ de $18^{\mathrm{e}}$ eeuw

Expositie weekenden met gastdeelnemers; 7/8/9 \& 14/15/16 augustus (11.00-17.00 uur)
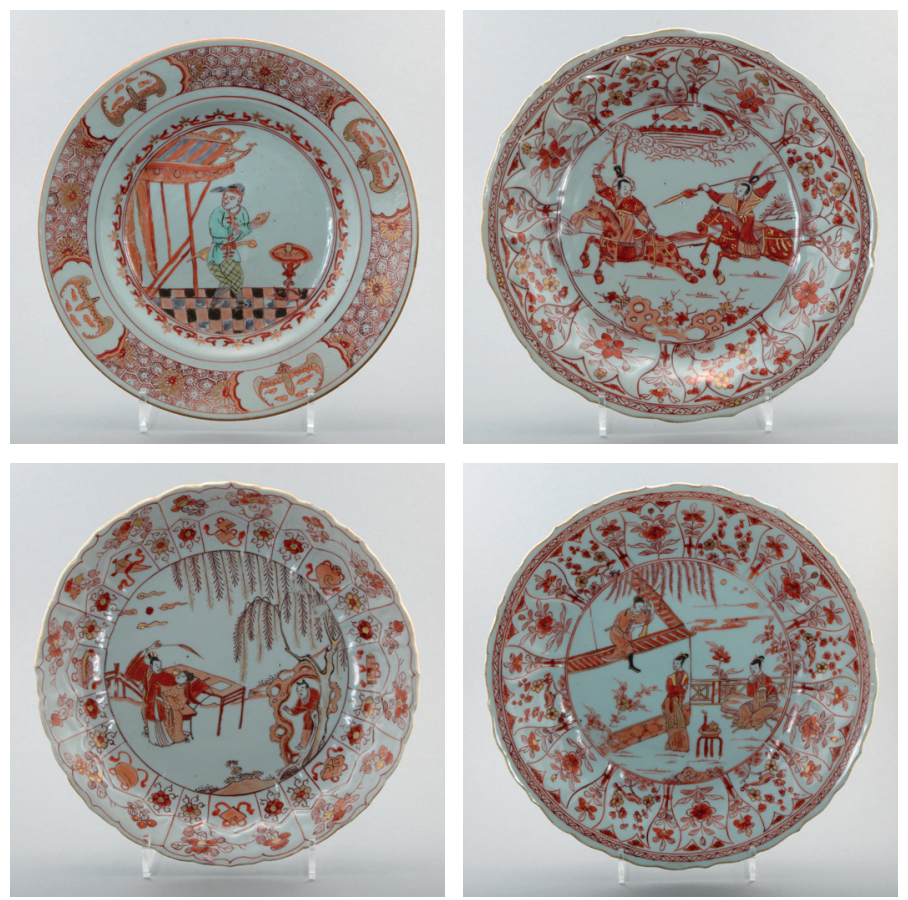

Collectie Chinese porseleinen melk en bloed borden.

Met voorstelling van een harlekijn, een Chine de Commande voorstelling van de 'Comedy del Arte' ca. 1740, de overige drie borden met voorstellingen van 'The Romance of the Western Chamber', Kangxi 1662-1722.

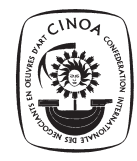

Adres:

Molenstraat 58/60 5341 GE Oss

(ruime eigen parkeergelegenheid aanwezig)
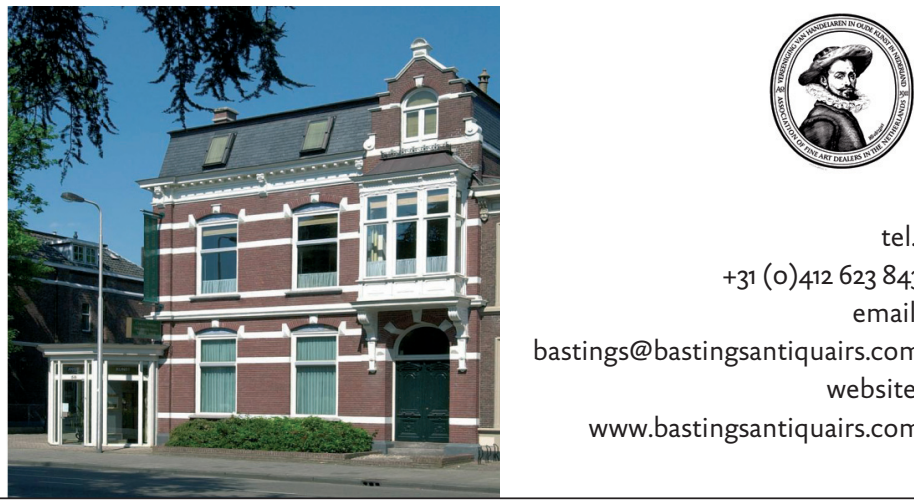

tel.: $+31(0) 412623843$ email: bastings@bastingsantiquairs.com website: www.bastingsantiquairs.com 


\section{AstamANGALA}

OUDE KUNST UIT TIBET, NEPAL EN INDIA

KEIZERSGRACHT 574 • 1017 EM AMSTERDAM (SPIEGELKWARTIER)

TEL: 020-6234402・E-MAIL: ASTA@XS4ALL.NL・WWW.ASTAMANGALA.COM

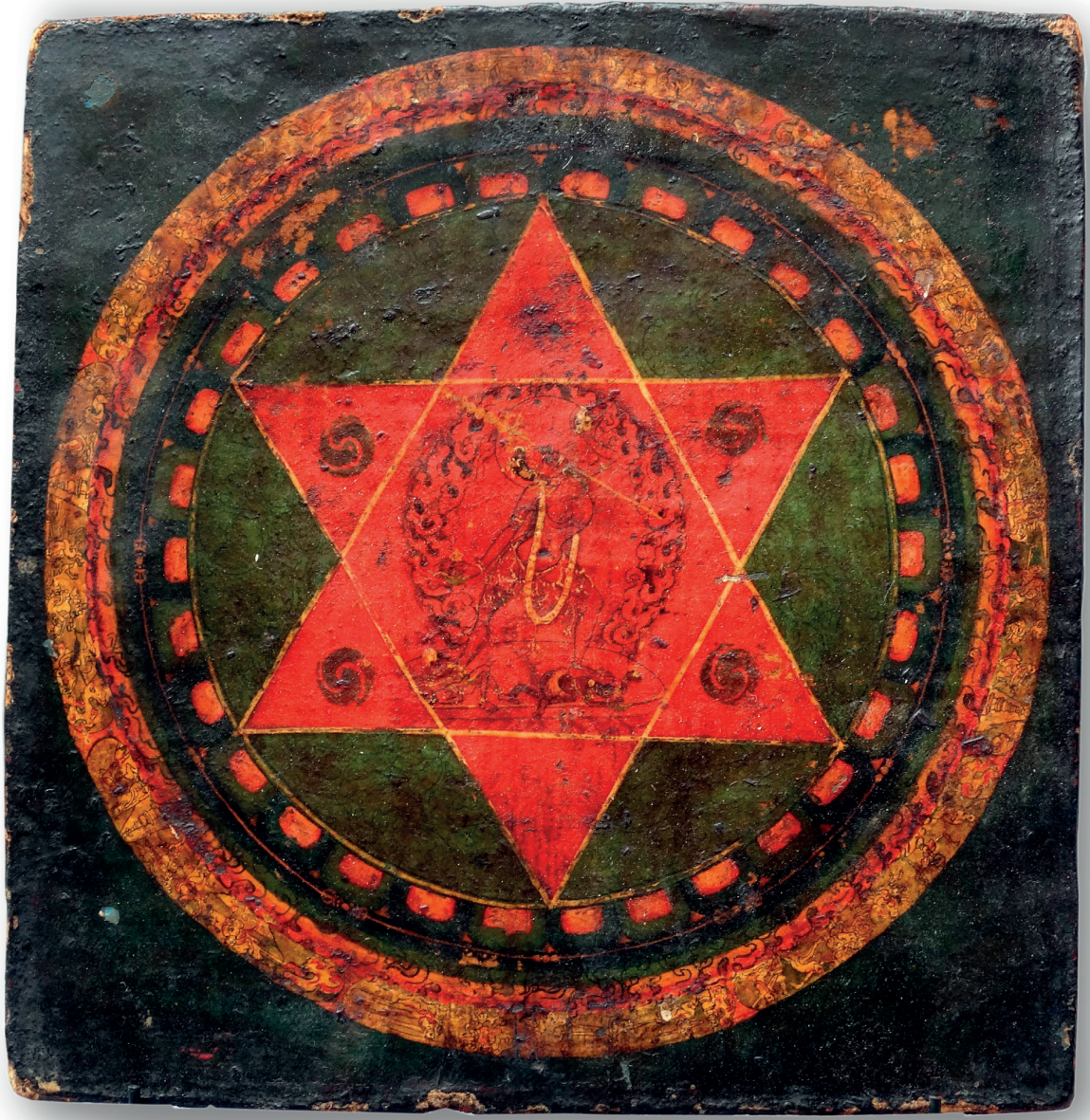

Mandala van Naro Dakini

verf op textiel en hout, Tibet, $17^{\text {de }}$ eeuw, afm.: $28 \times 28 \mathrm{~cm}$. 


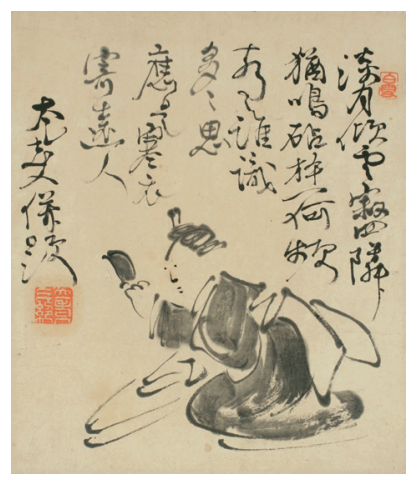

Murase Taiitsu (1803-188I)

Gekka ni chinsei. Het geluid van het kloppen van de wol. signatuur: Taiitsu Rôjin heidai, 26,2 x 22,6 cm.

Oranda Jin te gast bij galerie Jan van Hoof

Tentoonstelling van Japanse rolschilderingen en schilderskeramiek uit de I8e t/m 2oe eeuw, speciale 'gast' Murase Taiitsu (I803-I88I)

De expositie is te zien van 9 juli tot en met 26 juli 2015 .

Openingstijden donderdag $\mathrm{t} / \mathrm{m}$ zondag van $\mathrm{I} 4.00$ tot $\mathrm{I} 8.00$ uur en op afspraak. Vughterweg 58-60, 52II CM 's-Hertogenbosch.

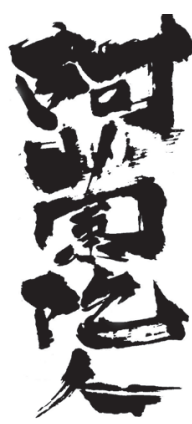

\section{ORANDA JIN}

Japanese paintings \& painters' pottery

Jon de Jong

Kalverstraat 28, 5223 AD 's-Hertogenbosch tel: $+31(0) 73-6218951$

e-mail: orandajin@home.nl

www.orandajin.com

(nieuwe update eerste week van de maand)

\section{Frides Laméris}

KUNST - EN ANTIEKHANDEL VOF

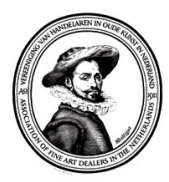

Nieuwe Spiegelstraat 55

IOI7 DD Amsterdam

Telefoon 020-6264066

info@frideslameris.nl

www. frideslameris.nl

glas - ceramiek

objets de collection

Kop en schotel beide met een beschildering van een schip, een eilandje, een vioolspelende meermin en rotsen in zee. Langs de rand op een banderol de inscriptie 'GARDES vous DE LA SYRENE'. Kangxi, eind zeventiende eeuw.

H. kop 4,9 cm, Ø 8,9 cm, Ø schotel I3,4 cm.

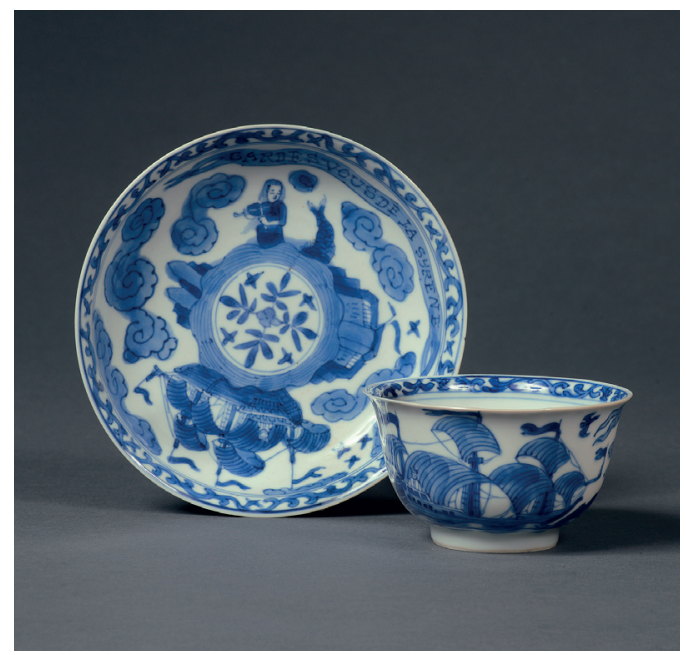




\section{Gallery China Art}

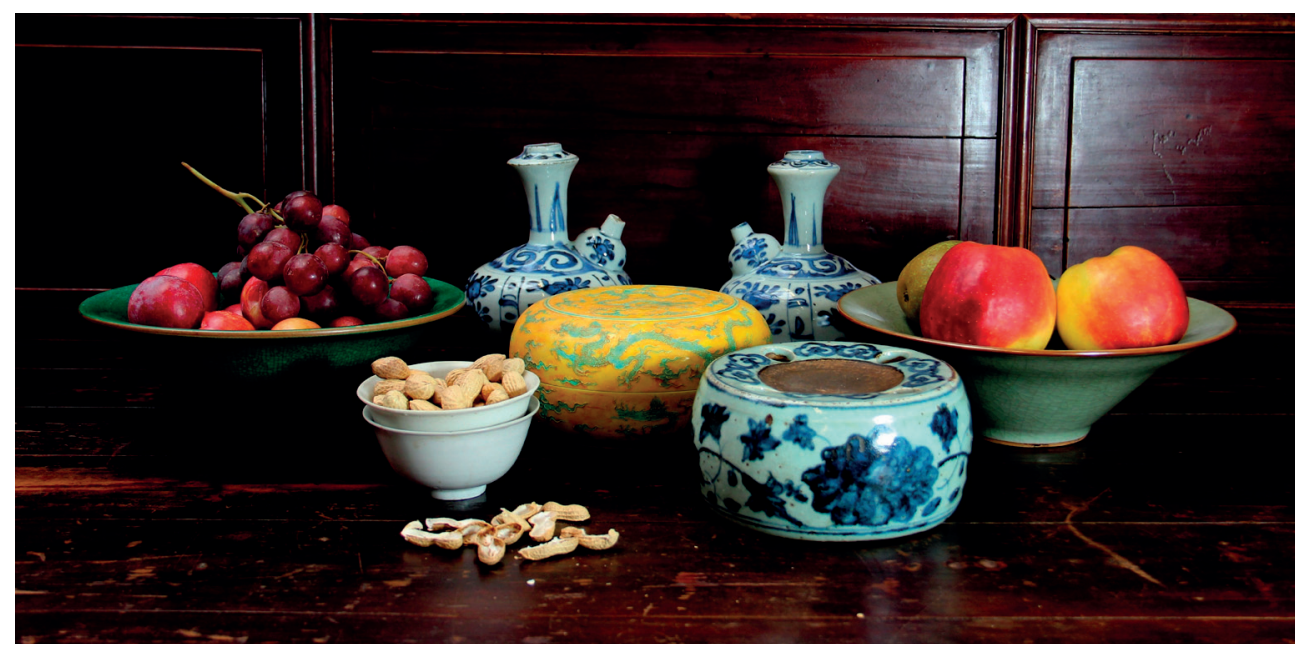

Chinese porseleinen uit de song ming qing dynasty

Mariniersweg 24 3011 NN Rotterdam

Tel: 010-229 3583

Openingstijden:

dinsdag t/m zaterdag van 11:00-17:00 uur en

zondag van 13:00-17:30 uur

mail: chinaartgallery@hotmail.com

www.gallery-china-art.nl 


\section{Kunst en Antiekveiling 10-13 november}

Kijkdagen: vrijdag 6, zaterdag 7 en zondag 8 november van 10.00 tot 17.00 uur
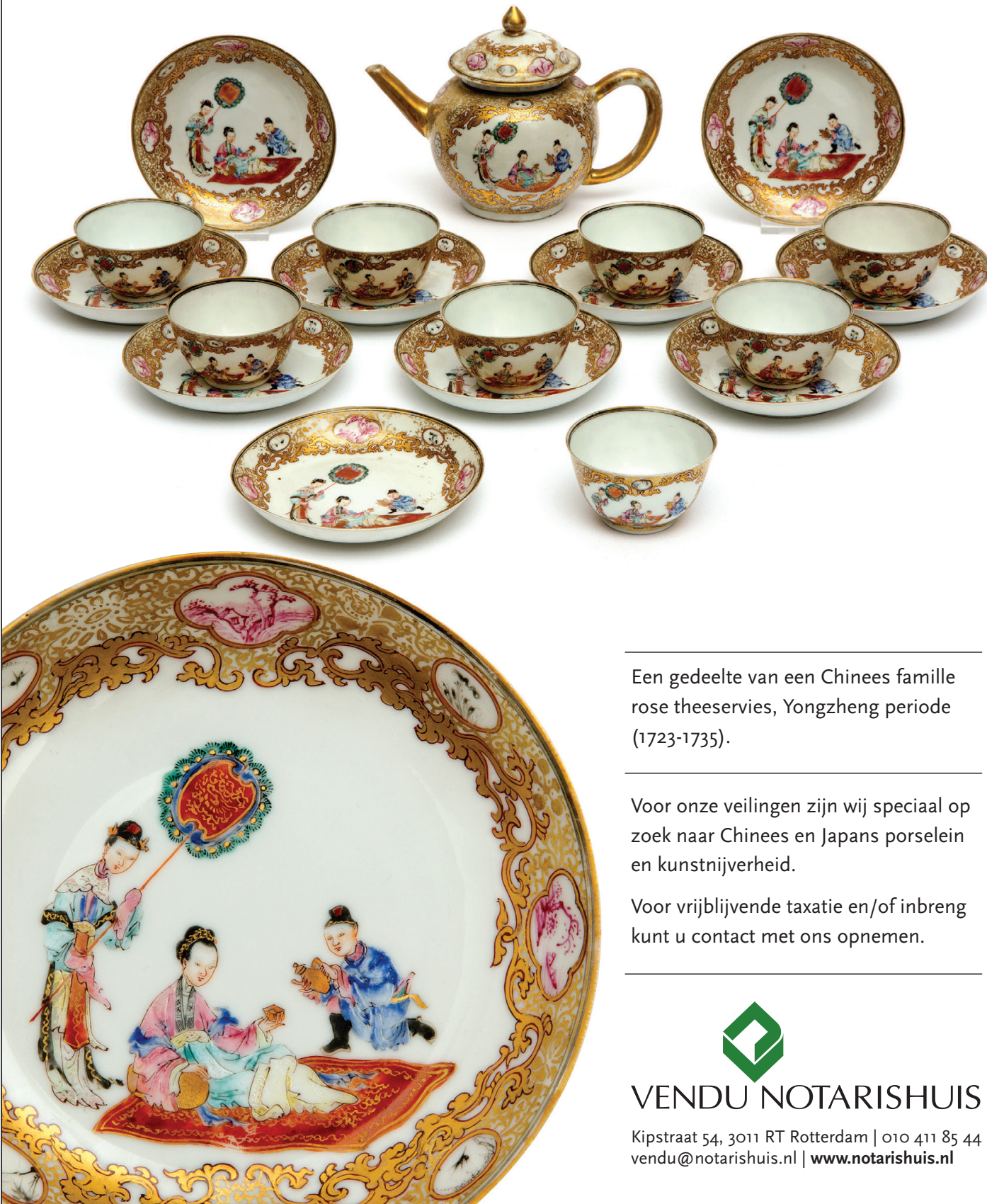

Een gedeelte van een Chinees famille rose theeservies, Yongzheng periode (1723-1735).

Voor onze veilingen zijn wij speciaal op zoek naar Chinees en Japans porselein en kunstnijverheid.

Voor vrijblijvende taxatie en/of inbreng kunt $u$ contact met ons opnemen.

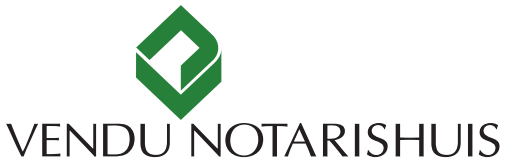

Kipstraat 54, 3011 RT Rotterdam | 0104118544 vendu@notarishuis.nl | www.notarishuis.nl 


\section{LEMPERTZ}

1845

Aziatische kunst

Uitnodiging voor inbreng voor onze herfstveilingen

Contact: +3I-(o)649318660 vanpruissen@lempertz.com

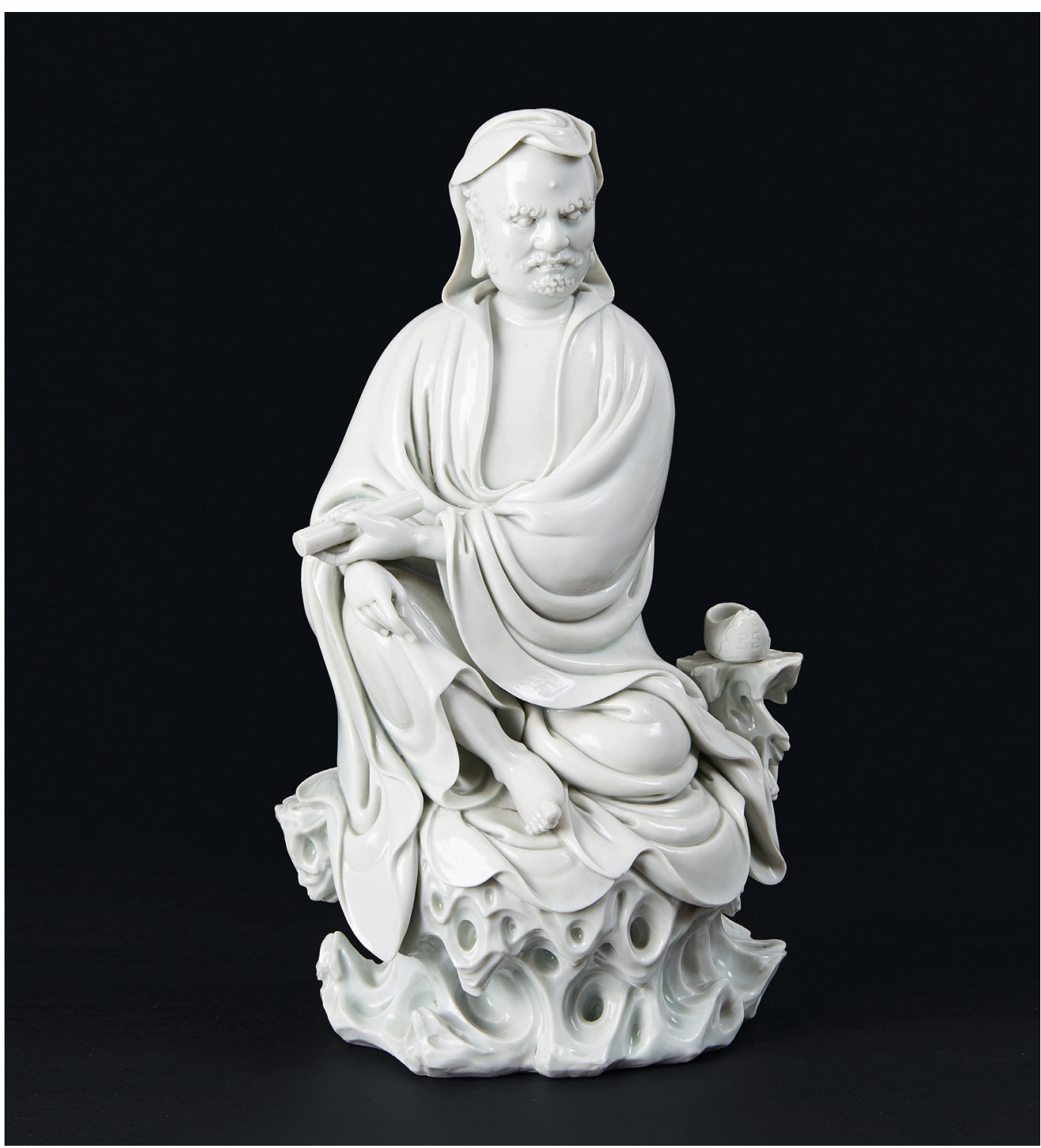

Blanc de Chine figuur van een zittende Damo. China, I7e eeuw. H 34,7 cm. Verkocht voor € 868.000,-

Neumarkt 350667 Keulen T +49-22I-92 57 29-37 [asian@eranpertr.ẹm l.com04/26/2023 02:36:42PM 


\section{MARCEL NIES ORIENTAL ART}

Lange Gasthuisstraat 282000 Antwerpen België marcelnies@skynet.be

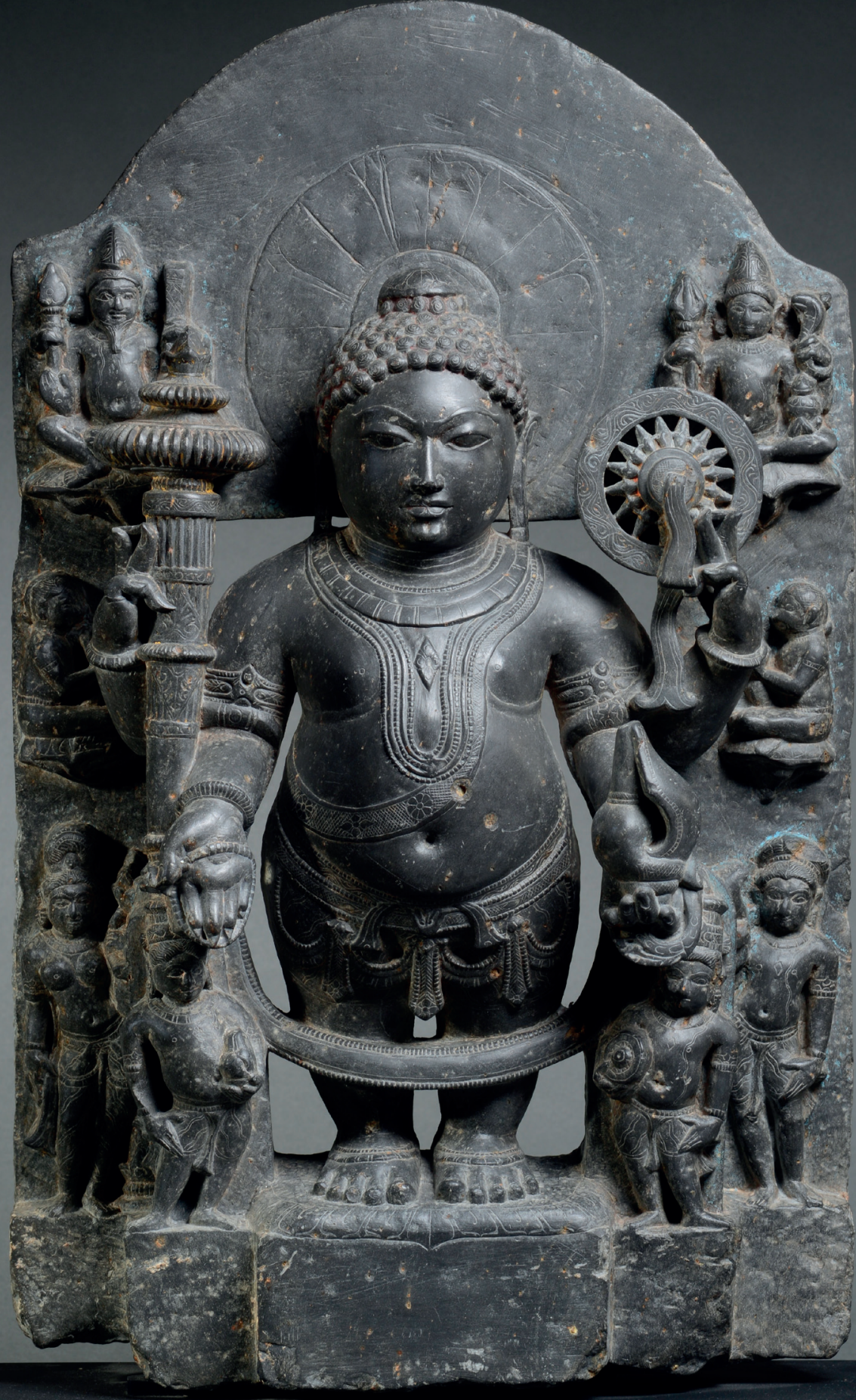




\section{GUUS RÖELL FINE ART}

Tel.: 0653211649 | e-mail: g.roell@planet.nl | website: www.guusroell.com Tongersestraat 2, $6211 \mathrm{LN}$ Maastricht

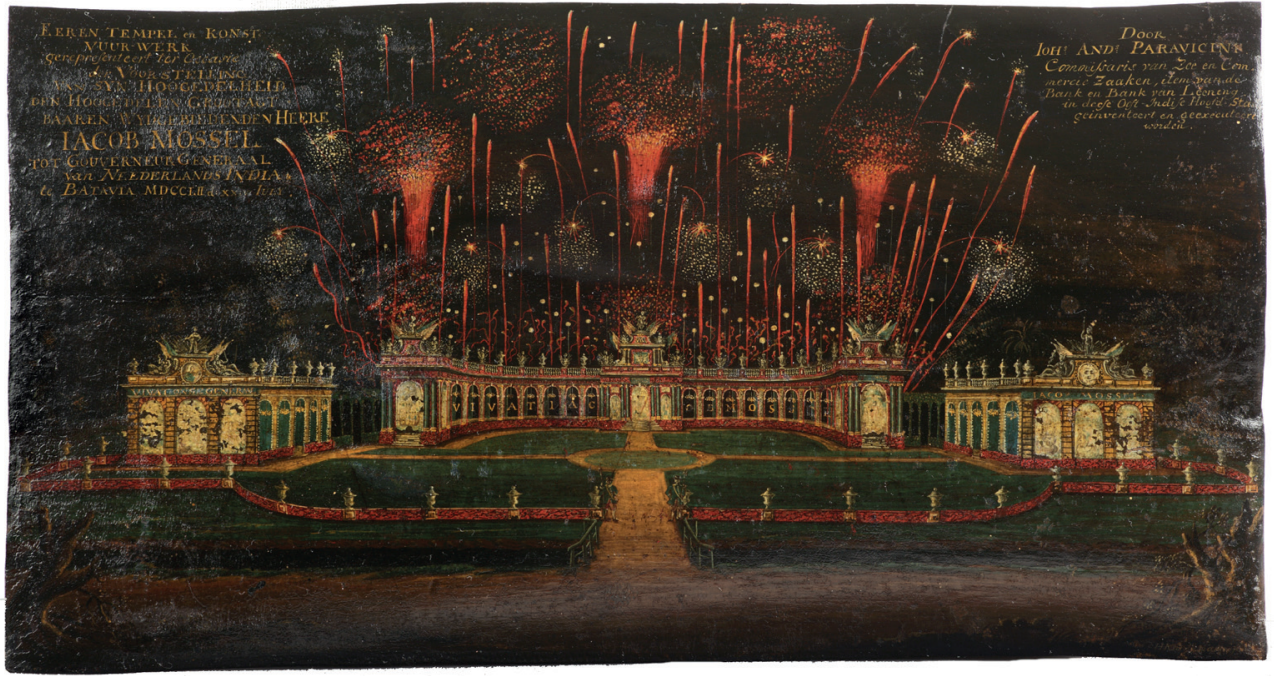

Olieverf op perkament, onduidelijk gesigneerd rechts onder. Met tekst, in samengevatting,

"Vuurwerk ter gelegenheid van de aanstelling van Jacob Mossel tot Gouverneur Generaal van Nederlands Indië te Batavia op 24 Juli 1752, bedacht en uitgevoerd door Johannes Andreas Paravicini, Commissaris van Zee en Commercie Zaken en van de Bank en Bank van Lening te Batavia”.

Jacob Mossel (Enkhuizen I704-Batavia 176I) kwam in I720 als I6-jarig zeeman in Batavia waar hij in 1750 werd benoemd tot Gouverneur Generaal. Paravicini (Barcelona I7IO-Stenay I77I) kwam in 1724 als I4-jarig ziekentrooster in Batavia waar hij opklom en door Jacob Mossel op diplomatieke missies werd gestuurd waarvan hij geschilderde representaties liet maken (Koninklijk Instituut voor de Tropen, inv. nr. 3728-540a en 54Ia). $16 \mathrm{~cm}$ bij 29,4 cm. 